\title{
Lontar Tutur Candrabherawa Perspektif Pendidikan Agama Hindu
}

\author{
Ida Ayu Gde Wulandari \\ Fakultas Dharma Acharya, IHDN Denpasar Email: \\ dayugdewulandari@gmail.com
}

\begin{abstract}
:
The literary works belonging to the traditional literary written in ancient times by using lontar. This tradition is still done until now aiming to bequeath literary treasure. One of the literary works that has educational values of Hinduism is Lontar Tutur Candrabhérawa. It tells about two king, namely Yudhistira, who ruled in the kingdom of Astina Pura and the Candrabhérawa who ruled in the kingdom of Dewantara. Both king have two different understanding, namely the concept of Karma Sanyasa and Yoga Sanyasa. It tells us that life does not separate from karma and yoga. The goals in this study is that the literary Lontar Tutur Candrabhérawa with its intrinsic structure which consist of a theme, characters, plot, incident, background, and mandate. Review from the function of education, based on the classification of Bloom's taxonomy, containing three functions of education, namely cognitive, affective and psychomotor. Meanwhile, when viewed from educational values of Hinduism, it contains religious, patriotism, environmental care, respect, and the right appointment. With these findings can be expected to create human characters that are religious, ethical, and social spirit in religious life.
\end{abstract}

Keywords: Tutur Candrabhérawa, the value of Hinduism, function

\begin{abstract}
Abstrak:
Karya sastra yang termasuk karya sastra tradisional pada jaman dahulu ditulis di atas daun lotar. Tradisi penulisan di atas daun lontar ini masih dilakukan sampai sekarang. Salah satu karya sastra yang mengandung nilai pendidikan agama Hindu adalah Lontar Tutur Candrabhérawa. Lontar Tutur Candrabhérawa menceritakan dua menceritakan dua raja, yaitu Raja Yudhistira yang memerintah pada kerajaan Astina Pura dan Raja Candrabhérawa memerintah pada kerajaan Dewantara. Raja Yudhistira memiliki pandangan memahami agama dalam ajaran karma sanyasa dan Raja Candrabhérawa memiliki pandangan dalam memahami agama dalam konsep yoga sanyasa. Hal ini mengajarkan kita bahwa hidup tidak bisa dipisahkan dari karma dan yoga. Tujuan dari penelitian ini adalah bahwa karya sastra Lontar Tutur Candrabhérawa dengan struktur intrinsik yang terdiri atas tema, karakter, alur, insiden, latar, dan amanat. Ditinjau dari fungsi pendidikan dalam klasifikasi taksonomi Bloom, memiliki tiga fungsi pendidikan, yaitu kognitif, afektif, dan psikomotor. Semestara itu, ditinjau dari nilai-nilai pendidikan agama Hindu, karya sastra ini memiliki nilai sikap beriman, cinta tanah air, sikap peduli lingkungan, sikap hormat, tepat janji. Dengan demikian diharapkan dapat menciptakan karakter religius, beretika dan semangan sosial dalam kehidupan beragama.
\end{abstract}

Kata kunci: Tutur Candrabhérawa, nilai Hindu, fungsi

\section{Pendahuluan}

Karya sastra dalam kehidupan manusia dapat dikatakan sebagai sebuah ekspresi jiwa seseorang atas hal yang pernah dialami dan dirasakan. Dalam menciptakan sebuah karya sastra, seseorang memerankan emosi, jiwa, dan pikirannya sehingga pembaca turut serta merasakan hal yang tertulis dalam karya tersebut. Maka dari itu, segala aspek 
kehidupan manusia dapat ditemukan dalam karya sastra, seperti halnya kehidupan manusia sebagai makhluk beragama.

Segala bentuk khazanah budaya khususnya dalam bidang karya sastra sangat beragam, khususnya khazanah sastra tradisional Bali. Khazanah sastra tradisional tersebut dapat berupa kakawin, babad, prosa, geguritan, tutur, dan kidung. Khazanah sastra tersebut masih tumbuh subur berkembang pada masyarakat Bali. Zaman dahulu hingga sekarang, naskah lontar dikenal sebagai hasil kreativitas pengarang untuk mengungkapkan buah pikiran, gagasangagasan yang ingin disampaikan kepada orang lain ataupun masyarakat luas. Disadari atau tidak, para penulis naskah lontar dalam penulisannya mengalami proses transenden. Para penulis naskah lontar tersebut tidak menyadari bahwa dirinya mengalami proses transenden. Oleh sebab itu, karya-karya yang dihasilkan memiliki nilaimagis, spiritual, religius, dan kekuatan yang mampu mentransformasi nilai-nilai tersebut ke dalam diri para penikmat sastra.

Karya sastra klasik (tradisional) di Bali masih banyak ditemukan dalam bentuk lontar yang ditulis dengan menggunakan aksara Bali. Karya lontar tersebut sudah banyak dialihaksarakan dan dialihbahasakan (ditransliterasi). Masyarakat Bali mempercayai bahwa naskah-naskah sangat sakral sehingga dalam membaca lontar harus melalui ritual khusus. Karya-karya sastra tersebut pada umumnya ditemukan dengan isi yang sarat dengan nuansa keagamaan yang mengandung nilai-nilai agama. Ikram (dalam Kusuma, 2005:2) menyatakan bahwa naskah-naskah lama merupakan sumber yang tidak ternilai bagi aspek kebudayaan karena mengandung gambaran yang cukup jelas mengenai pandangan hidup, adatistiadat, kepercayaan, dan sistem nilai pada masa lalu.

Keberadaan Lontar Tutur Candrabhérawa yang merupakan salah satu sumber naskah agama Hindu bertujuan untuk memperkuat dan memperkokoh jiwa keagamaan. Lontar Tutur Candrabhérawa sebagai sebuah karya sastra klasik (tradisional) menyimpan banyak nilainilai yang menjadi konsep-konsep keagamaan. Kusuma (2005:203) pun berpandangan serupa bahwa pada umumnya karya sastra Jawa Kuna mengandung konsep-konsep keagamaan. Namun, konsep-konsep keagamaan tersebut dalam karya sastra klasik oleh pengarangnya (para kawi) tidak disajikan secara teoritis, melainkan hanya diungkap hal-hal yang bersifat praktis, yaitu halhal yang sangat berguna dan bermanfaat bagi kehidupan.

Berdasarkan hal tersebut, Lontar Tutur Candrabhérawa sangat berguna dan bermanfaat dalam kehidupan. Hal ini didasarkan atas isi dari lontar tersebut yang isinya mengajarkan hal-hal yang paling mendasar dalam kehidupan beragama dan keagamaan. Oleh sebab itu, Lontar Tutur Candrabhérawa sebagai karya sastra klasik dapat dijadikan sebagai pedoman dalam kehidupan. Bahkan Robson (dalam Sura dkk, 2002:2) menguraikan bahwa dalam karya-karya sastra klasik terkandung sesuatu yang sangat penting dan berharga sebagai warisan rohani bangsa. Dengan mempelajari sastra, diharapkan mampu mendekati dan menghayati pikiran dan cita-cita luhur yang menjadi pedoman kehidupan mereka dahulu. Hal tersebut sangat diperlukan sebagai refleksi pada jaman sekarang. Mengingat berbagai aspek kehidupan dapat terungkap dalam Lontar Tutur Candrabhérawa naskah kuno Hindu, maka kajian teks Lontar Tutur Candrabhérawa sebagai naskah kuno Hindu penting dilakukan. Oleh karena itu, Lontar Tutur Candrabhérawa ini diangkat menjadi sebuah karya ilmiah.

\section{Pembahasan \\ Struktur Intrinsik Lontar Tutur Candrabhérawa}

Kajian stuktur menganalisis bangun cipta sastra dengan memperhatikan bagian dalam yang membentuk karya sastra itu sendiri. Dengan 
mengetahui bagan dalam inlah, maka nilai dan fungsi yang terdapat dalam Lontar Tutur Candrabhérawa dapat dianalisa dengan baik. Sejalan dengan pendapat Teeuw (1991:38) bahwa struktur sendiri merupakan sebuah bagian yang memainkan peranannya sendiri dan membentuk satu keseluruhan hingga membentuk karya sastra. Adapun struktur intrinsik yang dapat diuraikan dalam Lontar Tutur Candrabhérawa adalah sebagai berikut.

\section{Insiden}

Insiden merupakan unsur yang penting untuk mengembangkan alur dalam suatu sastra. Menurut Sukada (1987:59) kajian insiden dapat dilihat dari dua unsur yakni: 1) insiden pokok, dan 2) insiden sampingan. Insiden pokok adalah kajian yang mengandung ide-ide pokok cerita yang menjurus pada kesimpulan cerita yang menyebabkan terbentuknya alur (plot). Sedangkan insiden sampingan adalah insiden yang menyamping dari sebab akibat yang logis mengandung ide-ide sampingan. Karena itu insiden sampingan tidak menjurus atau menunjang kepada alur (plot).

Insiden-insiden yang terdapat dalam Lontar Tutur Candrabhérawa berdasarkan alur (plot) yang telah dijabarkan pada penjelasan sebelumnya adalah sebagai berikut.

a) Sang Bhima tiba di sebuah negeri yang berada di timur laut dengan keadaan wilayah yang megah, luas dan datar serta airnya mengalir tiada putusnya. Sang Bhima datang ke arah tersebut dan berisitrahat di bawah pohon sendirian. Di sana ia menemukan dua orang dan Sang Bhima mendekat di samping orang itu.

b) Insiden yang kedua adalah saat Sang Bhima meminta Brahma dan Wisnu untuk mengantarkannya kehadapan Prabhu Candrabhérawa.

c) Insiden yang ketiga yang terjadi dalam Lontar Tutur Candrabhérawa adalah Prabhu Yudhīștira mengutus patih Kiratha melalui pertimbangan Śrī Kṛ̣ṇa, untuk menyampaikan pesan kepada Prabhu Candrabhérawa agar menjalankan ajaran karma sanyasa. Apabila Prabhu Candrabhérawa menolak untuk menerapkan ajaran tersebut, maka kerajaan Dewantara akan diserang oleh kerajaan Astinapura.

d) Insiden keempat terjadi saat kerajaan Astinapura sudah tiba di kerajaan Dewantara dengan berbagai jenis pasukan dan persenjataan yang digunakan untuk menyerang negara Dewantara. Kedatangan pasukan dari kerajaan Astinapura dilawan oleh Patih Witaraga, Patih Mangkubhumi dan Patih Dewanantaka. Ketiga patih tersebut mati terbunuh oleh Sang Arjuna, Sang Bhima dan sang Nakula sehingga mundurlah semua prajurit Parya.

Insiden yang kelima adalah Prabhu Candrabhérawa bertemu dengan Prabhu Yudhīṣtira. Prabhu Yudhīștịa menjelaskan maksud kedatangannya menginginkan kematian Prabhu Candrabhérawa. Akhirnya atma Prabhu Candrabhérawa didapatkan di alam sunyaloka. Prabhu Candrabhérawa kalah oleh Raja Yudhīṣtira. Prabhu Candrabhérawa mempersembahkan putrinya yang cantik jelita, Diah Ratna Sasangka, kepada Raja Yudhīșțira.

\section{Alur (Plot)}

Alur atau plot memang sangat penting bagi sebuah cerita, melalui alur pembaca mengetahui rangkaian yang terdapat dalam suatu cerita (Suyitma, 1986:114). Alur yang terdapat dalam Lontar Tutur Candrabhérawa diceritakan secara berurutan, yaitu dari awal, tengah, dan akhir cerita. Dengan memperhatikan hal tersebut, maka alur yang tampak adalah alur maju atau lurus, yaitu mulai dari awal, tengah, dan diteruskan dengan bagian akhir. Alur ini sangat mudah dipahami oleh pembaca dan merupakan cara menceritakan peristiwa yang paling baik. Mengutip pendapatnya Lubis (1984:18) bahwa dijelaskan alur sebuah cerita dapat dibagi ke dalam lima unsur yaitu situation, generating circumtaties, rising action, climax, dan denouement. 


\section{Situation}

Tahap situation atau situasi merupakan sebuah rangkaian peristiwa yang dimulai dari kejadian atau keadaan awal dalam suatu cerita. Tahap pertama adalah menentukan alur yang berisi penggambaran dan pengenalan berupa situasi dan tokoh cerita. Bagian awal tersebut adalah sebuah permulaan awal cerita yang menunjukkan Panca Pandawa diutus oleh Raja Yudhīștira untuk mengunjungi dan desa-desa yang belum menjalankan ajaran karma sanyasa. Dari permulaan cerita inilah akan berkembang perjalanan Sang Bhima yang menemukan sebuah negara yang tidak menerapkan ajaran seperti yang diperintahkan oleh kakaknya, Sang Yudhīștira.

\section{Generating Circumtaties}

Rangkaian peristiwa berikutnya disebut dengan tahapan generating circumtaties yaitu permulaan terjadinya konflik merupakan rangkaian sebuah peristiwa atau kejadian dalam suatu cerita mulai bergerak. Pada tahapan ini, merupakan tahapan yang akan memunculkan konflik dan akan berkembang mencapai puncaknya. Jika dalam cerita Lontar Tutur Candrabhérawa, peristiwa mulai bergerak pada saat Bhima berselisih paham dengan Brahma dan Wisnu menjelaskan tentang agama yang dianut di negara Dewantara. Brahma dan Wisnu mengatakan bahwa di negara Dewantara tidak ada parhyangan, tidak ada sesaji, tidak ada upacara, dan tidak ada dewa. Bhima merasakan bahwa pengetahuan ajaran agama dari Brahma dan Wisnu sangat mendalam. Brahma dan Wisnu memberikan Bhima penjelasan mengenai hakekat Catur Wangsa dan wangsa dari Brahma dan Wisnu. Bhima mendengarkan penjelasan dari Brahma dan Wisnu yang sedemikian dalamnya sehingga Bhima sendiri merasa tidak bisa berbicara banyak karena dirinya merasa dikungkung oleh pikirannya. Hal ini membuat Bhima kebingungan dan mencari tahu tentang kerajaan Dewantara dan rajanya lebih lanjut.

\section{Rising Action}

Rising action adalah sebuah tahapan yang ditandai dengan peningkatan konflik pada sebuah peristiwa. Konflik yang telah dimunculkan pada tahap sebelumnya akan semakin berkembang dan bergerak menuju titik puncak. Peningkatan konflik pada Lontar Tutur Candrabhérawa terjadi saat Bhima merasakan bahwa Prabhu Candrabhérawa meremehkan orang yang membuat parhyangan, mempersembahkan banten, dan memuja dewa. Hal ini akan dilaporkan kepada Śrī Kṛ̣ṇa dan Yudhīștira. Bhima merasakan akan mengambil tindakan akibat hasil pertemuannya dengan Prabhu Candrabhérawa yang membuat diri Bhima harus melapor kepada kakaknya, yaitu Raja Yudhīștira. Dari permulaan sikap Bhima inilah yang kemudian menggiring cerita kepada keadaan klimaks dari cerita.

\section{Climax}

Tahap climax merupakan peristiwa dan kejadian yang mencapai titik puncak atau pertentangan-pertentangan yang terjadi dalam ceritamencapaiintensitas.Peristiwayangmencapai climax dalam Lontar Tutur Candrabhérawa adalah ketika utusan Patih Kiratha tiba di kerajaan Astinapura untuk menghadap kepada Prabhu Yudhīștira untuk menyampakan pesan Raja Candrabhérawa. Pesan tersebut membuat Maharaja Kṛṣna, Bhima, Arjuna, Nakula, dan Sahadewa marah.

Alur klimaks terjadi saat Patih Kiratha kembali tiba di kerajaanAstinapura menyampaikan hasil dari pertemuannya dengan Prabhu Candrabhérawa. Sikap Prabhu Candrabhérawa yang tidak taat pada perintah Yudhīștira menyulut kemarahan sehingga peperangan antara kerajaan Astinapura dengan kerajaan Dewantara tidak bisa dihentikan.

\section{Denouement}

Denouement adalah tahapan penyelesaian dari sebuah peristiwa dari sebuah kejadian. Dalam hal ini, pengarang memberikan pemecahan masalah atas semua kejadian dalam cerita. Dalam cerita yang terdapat dalam Lontar Tutur Candrabhérawa yang merupakan bagian dari 
tahapan penyelesaian atau denouement adalah saat Prabhu Candrabhérawa mengutarakan janjinya kepada Śrī Kṛṣna bahwa Prabhu Candrabhérawa mempertaruhkan putrinya yang bernama Dyah Ratna Sasangka dalam mengadu kesaktian dengan Raja Yudhīștira.

\section{Tokoh dan Penokohan}

Dalam Lontar Tutur Candrabhérawa menunjukkan bahwa Prabhu Yudhīștira, Sri Bhérawa, dan Śrī Kṛ̣ṇa sebagai tokoh utama. Sedangkan tokoh-tokoh lainnya adalah Bhima, Arjuna, Nakula, Sahadewa, Patih Kiratha, Brahma, Wisnu, walaupun kemunculannya agak terbatas, namun fungsinya tidak dapat diabaikan untuk mengukuhkan konsep-konsep keagamaaan yang terkandung dalam karya tersebut. Berikut ini adalah penjelasan dari tokoh-tokoh utama dan tokoh pendukung dalam Lontar Tutur Candrabhérawa adalah sebagai berikut.

a) Yudhīșțira

Dalam Lontar Tutur Candrabhérawa, Prabhu Yudhīștira sebagai raja Astina yang mengadu keaktian dengan Raja Candrabhérawa yang berasal dari Kerajaan Dewantara.

b) Prabhu Candrabhérawa

Prabhu Candrabhérawa adalah seorang raja di kerajaan Dewantara. Beliau memiliki istri bernama Dewi Bahnurasmi dan memiliki seorang putri yang cantik jelita bernama Dyah Ratna Sasangka. Beliau memiliki tanda mantri yang kesemuanya memiliki nama seperti nama dewadewa dalam asta dewata, yaitu Brahma, Iswara, Mahadewa, Wisnu, Sambhu, Mahesora, Rudra, dan Sangkara. Prabhu Candrabhérawa memiliki karakter yang percaya dan yakin dengan keyakinannya, malu mengakui kekurangan dan berpegang teguh dengan pendirian.

c) Sri Kṛṣna

Sri Kṛṣna adalah titisan Dewa Wisnu yang menjelma ke dunia untuk menegakkan dharma melawan adharma. Tokoh Sri
Kṛṣna dalam Lontar Tutur Candrabhérawa Sri Kṛ̣ṇa mengambil peran dalam memberi pertimbangan dan keputusan kepada kerajaan Astinapura agar diutusnya Patih Kiratha ke kerajaan Dewantara untuk bertemu dengan Sri Bhérawa untuk menyampakan pesan Prabhu Yudhīṣțira.

d) Bhima

Tokoh Bhima dalam Lontar Tutur Candrabhérawa memiliki perwatakan yang memegang teguh agama dan membela kebenaran. Hal ini tercermin dalam ucapannya ketika berbicara dengan Prabhu Candrabhérawa untukmenjelaskan misinya ke kerajaan Dewantara bahwa misinya datang ke kerajaan Dewantara adalah untuk menegakkan ajaran agama sehingga tidak terjadi hal-hal yang bertentangan dengan agama.

e) Arjuna

Dalam Lontar Tutur Candrabhérawa, Arjuna memiliki watak yang pemberani dan ahli dalam ilmu perang.

f) Nakula dan Sahadewa

Nakula dan Sahadewa adalah putra kembar dari Dewi Madri. Nakula dan Sahadewa adalah putra dari Dewa Aswin. Dalam Lontar Tutur Candrabhé rawa, Nakula dan Sahadewa memiliki watak yang pemberani terutama dalam berperang.

g) Patih Kiratha

Patih Kiratha adalah seorang patih yang diutus oleh kerajaan Astinapura untuk menghadap Prabhu Candrabhérawa. Patih Kiratha dipercaya oleh Sri Kṛș̣a untuk menyampaikan pesan Raja Yudhīștira ke kerajaan Dewantara. Patih Kiratha memiliki karakter patuh kepada perintah raja.

h) Brahma dan Wisnu

Dalam Lontar Tutur Candrabhérawa, Brahma dan Wisnu adalah tanda mantri dari Prabhu Candrabhérawa. Brahma dan Wisnu adalah dua bersaudara. Kedua bersaudara memiliki watak yang setia kepada ajaran agama dan sangat memahami isi atau hakekat ajaran ag- 
ama. Brahma dan Wisnu adalah tokoh yang mengantarkan Bhima menghadap Prabhu Candrabhérawa di kerajaan Dewantara

\section{Tema}

Tema merupakan bagian pertama yang menentukan jalinan peristiwa selanjutnya juga menjiwai seluruh bangun cipta karya secara utuh. Pengertian tema menurut Sudjiman (1988:50) adalah ide pokok sebuah cerita dan merupakan hal terpenting di dalam cerita sebagai tujuan yang ingin disampaikan pengarang kepada pembaca lewat karyanya. Menurut Esten (1982:91) tema merupakan apa yang menjadi persoalan dalam sebuah karya sastra. Persoalan dalam karya sastra adalah tema, dengan kata lain setiap satu insiden yang paling menonjol maka itulah temanya. Mencermati pendapat di atas, titik pengertiannya tertumpu pada sebuah peristiwa yang paling jelas atau spektakuler sebagai sebuah pokok permasalahan, maka dengan demikian hal tersebutlah yang dinamakan dengan tema.

Mencermati beberapa peristiwa dalam penggalan tersebut di atas, dapat dinyatakan bahwa tema dalam Lontar Tutur Candrabhérawa adalah proses pencarian jati diri sebagai sebuah bentuk proses pendidikan dalam agama Hindu yang dilandasi ajaran tattwa, susila, dan acara masingmasing ajaran yang sekaligus akan membentuk sebuah pendidikan karakter. Meskipun pada tahap awal cerita dalam Lontar Tutur Candrabhérawa ini berada pada perbedaan konsep ajaran agama yang mendasar yang menimbulkan perselisihan dan konflik (perang), namun kedua ajaran tersebut dapat menyatu dan berjalan dengan damai tanpa menimbulkan konflik. Hal ini dapat terlihat dalam percakapan dan peristiwa yang senantiasa berkaitan dengan kedua konsep mendasar sebagai bentuk menjalani kehidupan beragama dan keberagamaan.

\section{Latar}

Menurut pendapat Sudjiman (1988:16) latar adalah segala keterangan petunjuk, pengakuan yang berkaitan dengan waktu, ruang dan suasana suatu cerita. Pada hakekatnya merupakan kejadian yang dilakukan oleh satu atau beberapa orang tokoh pada satu tempat dan waktu tertentu. Tidak mungkin dalam cerita tanpa adanya latar yang mengiringi kejadian-kejadian dalam karya sastra tersebut. Sejalan dengan pendapatnya Nurgiyantoro (1995:227-233) bahwa unsur latar dapat dibedakan menjadi tiga unsur pokok, yaitu latar tempat, latar waktu, dan latar sosial.

Latar waktu dan sosial tidak diceritakan secara implisit dalam teks salinan Lontar Tutur Candrabhérawa sehingga tidak bisa ditentukan latar waktu dan latar sosial dari cerita tersebut. Berdasarkan hal tersebut di atas, maka latar tempat terjadinya cerita tersebut yaitu wilayah Dewantara, kerajaan Dewantara, dan alam sunyaloka.

\section{Amanat}

Amanat adalah hal yang sangat penting menjadi inti yang hendak disampaikan dari seorang penulis kepada para pembacanya. Maka dari itu, dalam sebuah karya sastra dapat ditemukan suatu ajaran moral dan pesan yang ingin disampaikan pengarang lewat medium bahasa yang disebut dengan amanat. Menurut Sudjiman (1988:58) menyatakan bahwa amanat dalam karya sastra tersurat secara implisit dan eksplisit. Implisit jika jalan keluar atau ajaran moral itu disiratkan dalam tingkah laku, sedangkan eksplisit, jika pengarang menyampaikan seruan, peringatan, nasehat, anjuran, larangan, dan sebagainya.

Sesuai dengan kutipan di atas, pengawi Lontar Tutur Candrabhérawa inginmenyampaikan pesan kepada para pembaca dengan bahasa yang dengan mudah dapat dimengerti dan dipahami. Dengan karya sastra, pengawi ingin mengajak para pembaca untuk menyikapi terhadap fakta dalam kehidupan nyata. Jadi, pesan atau amanat yang hendak disampakan oleh pengawi dapat diterima oleh pembaca dan semaksimal mungkin dapat dilakukan serta diaplikasikan dalam kehidupan nyata.

Oleh sebab itu, maka pesan mendalam 
yang terdapat dalam Lontar Tutur Candrabhérawa adalah sebuah pesan moral mengenai konsep ajaran beragama yaitu karma sanyasa dan yoga sanyasa. Lebih spesifik lagi adalah berkaitan dengan bhakti umat kepada Ida Sang Hyang Widhi Wasa dalam menjalankan dharma di dunia. Maka, amanat yang ingin disampaikan dari seorang pengawi kepada pembaca, khususnya dalam dunia pendidikan adalah seorang bhakta (pengikut ajaran bhakti) hendaknya melaksanakan ajaran karma sanyasa di dunia ini. Ajaran yoga sanyasa hanya dijalankan dalam diri saja. Dengan demikian, seluruh umat akan merasakan keselamatan dunia apabila umat menjalankan kedua konsep ajaran agama tersebut.

\section{Fungsi Pendidikan Agama Hindu Dalam Lontar Tutur Candrabhérawa Fungsi Pendidikan Tattwa}

Tattwa sama dengan filsafat. Keraf (2001) menyatakan bahwa filsafat adalah upaya, proses, metode, cara, dambaan untuk terus mencari kebenaran. Berdasarkan pandangan tersebut, maka kebenaran yang akan dikejar terus adalah nilai-nilai kebenaran agama Hindu.

Berdasarkan konteks penelitian ini, maka yang dimaksud dengan fungsi pendidikan tattwa adalah ranah kognitif. Menurut Kamus Besar Bahasa Indonesia, kognitif adalah berhubungan dengan atau melibatkan kognisi; berdasar kepada pengetahuan faktual yang empiris (2008:712). Menurut Arikunto (2009:116), domain kognitif berisi perilaku-perilaku yang menekankan aspek intelektual yang tingkatannya adalah pengetahuan, pemahaman, aplikasi, analisis, sintesis, dan evaluasi.

Untuk mencapai tujuan hidup sebagai umat beragama Hindu, yaitu menuju kedamaian sekala dan niskala serta mencapai kebenaran abadi, maka umat Hindu dapat melakukannya dengan cara pemahaman tattwa sehingga tujuan tersebut dapat tercapai. Prabhu Candrabhérawa mengungkapkan bahwa dalam diri adalah sebuah alam kecil (mikrokosmos) yang sama halnya dengan dunia yang lebih besar (makrokosmos). Alam mikrokosmos dan makrokosmos adalah simbol alam yang sama-sama memiliki bagian, seperti sapta patala, sapta gangga, saptāgni, sapta parwata, sapta sunya, sapta sagara, danlain-lain.

Dalam konteks pendidikan agama Hindu khususnya dihubungkan dengan fungsi kognitif, pernyataan Prabhu Candrabhérawa ini adalah sebuah pengetahuan yang memberikan kesadaran diri sehingga manusia tahu akan diri dan hakikat diri. Ketika manusia sudah tahu terhadap diri, maka manusia dapat terhindar dari pengaruh awidya (kegelapan). Hal ini sesuai dengan salah satu tujuan pendidikan, yakni mendidik manusia dari tidak tahu menjadi tahu. Sehingga Lontar Tutur Candrabhérawa ini sarat memiliki fungsi kognitif yang menyadarkan manusia menjadi lebih mulia. Selain itu, juga dileaskan dalam penggalan teks tersebut menjelaskan ajaran tattwa diatmika. Tattwa diatmika adalah ajaran kesucian dan kebenaran yang diperoleh dalam keseharian dengan pendeta guru. Tattwa diatmika adalahajaran kesucian dan kebenaran yang merupakan cermin yang memiliki nilai pendidikan Tattwa sebagai pedoman umat dalam mengimplementasikan ajaran agama Hindu khususnya tentang tattwa.

Demikian pula halnya sebuah ajaran dharma (kebenaran) mengenai hakikat diri. Dengan memahami hakikat diri maka manusia tidak terikat dengan hal-hal yang bersifat duniawi, seperti keremajaan, penampilan fisik, dan sebagainya. Ajaran Prabhu Candrabhérawa ini menambah wawasan dan pengetahuan (kognitif) sehingga Lontar Tutur Candrabhérawa ini patut dijadikan pedoman dalam memperkuat kognisi dalam kehidupan beragama. Pernyataan Prabhu Candrabhérawa ini apabila dikaitkan dengan konsep paňca sradha maka dapat dianalisis melalui dua konsep sraddha, yaitu atman sradha dan mokșa. Atman secara eimologisberarti percikan-percikan kecil dari Ida Sang Hyang Widhi Wasa. Atman dalam Bhagavad Gita disebutkan merupakan bagian dari rambut- 
rambut Tuhan. Hakekat atman dan Brahman adalah sama sehingga Brahman dan atman adalah satu yang dijelaskan pada sloka Brahman atman aikyam. Konsep ini menurunkan ajaran tat tvam asi yang berarti Itu adalah aku. Itu yang dimaksud adalah inti dari hakekat sesungguhnya sedangkan aku adalah raga. Berdasarkan hal tersebut, ajaranajaran yang dijawantahkan oleh Prabhu Candrabhérawa bertujuan untuk mengingatkan diri terhadap kesejatian Brahman sebagai sumber dari segala sumber.

Pernyataan Prabhu Candrabhérawa ini mengenai ajaran saptāgni, sapta gangga, sapta patala, dan lain-lain jguga memiliki korelasi dengan ajaran mokșa. Mokșa adalah bagian dari paňca sradha. Mokșa diartikan sebagai penyatuan Brahman dengan atman. Penyatuan Brahman dengan atman dapat memutuskan rantai ikatan keduniwawian sehingga dapat mencapai kelepasan sejati. Istilah ini juga disetarakan dengan konsep suka tan pawali duka. Ajaran tentang diri yang dilontarkan oleh Prabhu Candrabhérawa adalah ajaran yang menunjukkan kesejatian yang menuntun umat manusia ke dunia mokșa. Manusia dapat mencapai mokșa tidak hanya pada saat meninggal dunia, tetapi juga dapat dicapai ketika masih hidup. Dalam ajaran agama Hindu, moksa juga terdapat tingkatan-tingkatannya. Cara mencapai tujuan akhir dan tertinggi dalam agama Hindu hanya dapat dicapai ketika manusia memahami ajaran hakekat diri yang dilontarkan oleh Prabhu Candrabhérawa. Oleh karena itu, pernyataan Prabhu Candrabhérawa sarat dengan pendidikan tattwa yang mengajarkan tentang filsafat agama Hindu.

\section{Fungsi Pendidikan Susila}

Kesusilaan berbentuk kaidah-kaidah yang berisi larangan-larangan atau perintah-perintah untuk berbuat sesuatu. Dengan demikian dalam etika kita akan dapatkan ajaran tentang perbuatan yang baik dan perbuatan yang buruk. Perbuatan yang baik itulah agar dilaksanakan dan perbuatan yang buruk itulah harus dihindari (Sura, 2006:16). Sebagai ilmu etika mencari kebenaran dan sebagai filsafat, etika mencari keterangan (benar) sedalamdalamnya. Etika mencari ukuran baik buruk bagi tingkah laku manusia, ada yang menyebut etika itu filsafat kesusilaan karena etika hendak mencari ukuran mana yang susila itu, artinya tindakan manusia manakah yang baik (Poedjawijatna, 1982:6).

Untuk lebih menyatukan persepsi dalam memahami fungsi pendidikan susila dalam dunia pendidikan modern adalah fungsi afektif. Menurut Kamus Besar Bahasa Indonesia, afektif adalah berkenaan dengan perasaan (seperti takut, cinta); mempengaruhi keadaan perasaan dan emosi; mempunyai gaya atau makna yang menunjukkan perasaan (gaya bahasa atau makna) (2008:14). Menurut Arikunto (2009:116), afektif berisi perilaku-perilaku yang menekankan aspek perasaan dan emosi dengan tingkatannya adalah pengenalan, merespon, penghargaan, pengorganisasian, dan pengamalan.

Keberadaan Lontar Tutur Candrabhérawa dalam hubungannya dengan fungsi afektif dalam hal ini adalah memiliki fungsi yang sama dengan etika sebagai wujud pembentukan perilaku yang susila. Hal tersebut dapat dicermati dalam ajaranajaran yang termuat di dalamnya sebagai konsep agama Hindu yang bertujuan untuk membentuk etika sehingga fungsi afektif dapat terpenuhi.

Dalam penggalan teks tersebut maka dapat dijelaskan mengenai ajaran susila dari sebuah wangsa. Agama Hindu memberikan pengelompokan atas wangsa menjadi empat bagian, yaitu wangsa brahmana, ksatriya, wesya, dan sudra. Keempat wangsa ini memiliki tugas dan tanggung jawab masing-masing. Tugas dan tanggung jawab masing-masing wangsa tersebut dalam Bhagavad Gita dikelompokkan berdasarkan guna dan karmanya.

Pernyataan Brahma dan Wisnu dalam penggalan teks tersebut memberikan penjelasan mengenai tugas dan kewajiban dari masing-masing wangsa yang ada di kerajaan Dewantara. Rakyat 
kerajaan Dewantara juga mengenal keempat wangsa tersebut dengan baik. Keempat wangsa yang terdapat dalam penggalan teks tersebut dapat dijelaskan sebagai berikut.

1. Wangsa Brahmana adalah wangsa yang mengetahui isi ajaran brahmana tattwa, mengetahui tujuan puja mantra, dan hakikat sapta gangga dan mudranya selengkapnya, luput dari keinginan pada wanita terlarang, luput dari perselisihan, tidak berbohong, tidak memfitnah, tidak cacat jasmani, tidak berjudi, hanya Dharmasastra yang dibicarakan tiap-tiap hari, makan serba suci, dan tidak menyombongkan diri.

2. Wangsa ksatrya adalah wangsa yang mengetahui tentang tugas-tugas raja dan asta aiswarya, memanfaatkan caturdasa upaya (empat belas siasat), sayang kepada rakyat, paham akan hakikat catur wangsa, berusaha mensejahterakan masyarakat, mencermati pancadreta, tetap memberikan sumbangan, tetap menjatuhkan hukuman, tidak tunduk pada yang bertentangan dengan dharma, setia pada tindakan dan kata-kata, tidak takut pada musuh yang sakti, tahu membimbing rakyat, menaruh kasih sayang pada mereka yang sengsara, tidak menyantap setiap makanan, tidak mau mengawini wanita terlarang, menerapkan kandungan isi ajaran suci, dan mengajarkan dharma kebajikan kepada masyarakat.

3. Wangsa Weisya adalah wangsa yang bekerja lahan kering dan sawah, tahu akan umur umbi-umbian dan buah-buahan, selalu mengusahakan kemakmuran negara, mengetahui tepat atau tidaknya sumbangan, setia bakti kepada sang dwijati, cakap berbahasa sor (bahasa untuk sesama atau merendahkan diri) dan singgih (bahasa untuk orang yang dihormati), paham akan sifat dasar masyarakat, basah keringnya tanah, dan tahu akan umur tuanya padi.

4. Wangsa Sudra adalah wangsa yang patut akraya, wikraya, kraya wikraya ialah berjual beli, berdagang berlayar dengan perahu, membuat makmurnya rakyat, mengusahakan uphaboga untuk rakyat, uphaboga adalah segala macam pakaian dan kain-kain, mendatangi negeri-negeri yang jauh, membawa jauh apa yang dekat, bakti kepada sang tri wangsa, dan dapat dijadikan kaki tangan sang prabhu.

Dalam penggalan teks tersebut juga mengetengahkan aspek-aspek etika yang disebut dengan Purwa Dharma Sasana atau tradisi kuno. Tradisi itu konon berasal dari dewa Siwa yang kemudian diikuti oleh seluruh dewa dan Raja Yudhīștira. Konsep Purwa Dharma Sasana mengandung ajaran tri kaya parisuda, pembuatan parhyangan, penyelenggaraan upacara bagi manusia dari lahir hingga mati dan upacara untuk keselamatan dunia. Fungsi afektif sangat terlihat jelas pada penggalan teks tersebut karena mempengaruhi aspek perasaan sehingga manusia lebih peka dengan dunia sekitarnnya. Hal ini sesuai dengan pendapat dari J.J Rousseau (Ahmadi, 2001:134) yang mengatakan bahwa tujuan pendidikan adalah mengembangkan anak itu menurut alamnya.

\section{Fungsi Pendidikan Acara}

Acara adalah tata cara pelaksanaan ajaran agama yang diwujudkan dalam tradisi upacara sebagai wujud simbolis komunikasi manusia dengan Tuhannya. Acara agama adalah wujud bhakti kehadapan Ida Sang Hyang Widhi Wasa dan seluruh manifestasinya. Pada dasarnya acara agama dibagi menjadi dua, yaitu upacara dan upakara. Upacara berkaitan dengan tata cara ritual, seperti tata cara sembahyang, harihari suci keagamaan (wariga), dan rangkaian upacara. Sebaliknya, upakara adalah sarana yang dipersembahkan dalam upacara keagamaan.

Untuk lebih menyatukan persepsi dalam memahami fungsi pendidikan acara apabila dihubungkan dengan pendidikan modern adalah fungsi psikomotorik. Dalam Kamus Besar Bahasa Indonesia, psikomotor adalah berhubungan dengan aktivitas fisik yang berkaitan dengan proses mental dan psikologi (2008:1109). Menurut Arikunto (2009:116), domain psikomotor berisi 
perilaku-perilaku yang menekankan aspek keterampilan motorik dengan tingkatannya adalah peniruan, penggunaan, ketepatan, perangkaian dan naturalisasi.

Dalam teks dinyatakan secara jelas bahwa setelah melewati pertarungan sengit antara kedua belah pihak, yakni antara Prabhu Yudhīsțira dengan Raja Candrabhérawa maka Kerajaan Dewantara telah tunduk dengan kerajaan Astina Pura. Kerajaan Dewantara menjalankan hakikat pelaksanaan karma sanyasa, yang meliputi pelaksanaan yajňa dan pendirian parhyangan. Begitu pula halnya dengan aturan-aturan lain yang disampaikan oleh Prabhu Yudhīṣtira agar dijalankan di kerajaan Dewantara dan tidak ada yang berani melanggar perintah Yudhīṣtira.

Dalam fenomena keberagamaan Hindu di Bali, acara agama tampaknya lebih menonjol dibandingkan dengan aspek lainnya. Acara agama yang seringkali juga disebut upacara atau ritual keagamaan merupakan pengejawantahan tattwa dan susila. Acara agama meliputi keseluruhan dari aspek persembahan dan bhakti kepada Tuhan Yang Maha Esa / Ida Sang Hyang Widhi Wasa yang disebut yajňa. Pada dasarnya yajňa dalam agama Hindu dapat dibagi menjadi dua, yaitu nitya karma dan naimittika karma. Nitya yajňa adalah yajn̆a yang dilaksanakan sehari-hari, misalnya yajňa sesa atau mesaiban. Sebaliknya, naimittika yajňa adalah yajňa yang dilaksanakan secara berkala atau pada waktu-waktu tertentu, misalnya pada saat piodalan, rerahinan, dan hari raya keagamaan Hindu lainnya (Tim Penyusun, 2005).

Dari ketiga pengertian tri kerangkaagama Hindu di atas semakin jelas bahwa ketiganya memang tidak dapat dipisahkan. Tattwa menjadi landasan teologis dari semua bentuk pelaksanaan ajaran agama Hindu. Susila menjadi landasan etis dari semua perilaku umat Hindu dalam hubungannya dengan Tuhan, sesama manusia, dan dengan alam lingkungannya. Sedangkan ācāra menjadi landasan perilaku keagamaan, tradisi, dan kebudayaan religius. Ācāra mengimplementasikan tattwa dan susila dalam wujud tata keberagamaan yang lebih riil dalam dimensi kebudayaan.

Tanpa adanya $\bar{a} c \bar{a} r a$, agama hanyalah seperangkat ajaran yang tidak akan nampak dalam dunia fenomenal. Secara sosio-antropologis, àcāra menjadi identitas suatu agama karena ia melembaga dalam sebuah sistem tindakan. Sebaliknya, tattwa (Ketuhanan) sangat abstrak sifatnya, demikian halnya dengan susila yang tidak hanya dibentuk oleh agama, melainkan juga oleh tradisi, adat, kebiasaan, tata nilai dan normanorma sosial.

\section{Nilai-Nilai Pendidikan Agama Hindu dalam Lontar Tutur Candrabhérawa}

Kata nilai berasal dari kata dalam bahasa Latin vale're yang artinya berguna, mampu akan, berdaya, berlaku, sehingga nilai diartikan sebagai sesuatu yang dipandang baik, bermanfaat dan paling benar menurut pendapat seseorang atau sekelompok orang. Nilai adalah kualitas suatu hal yang menjadikan hal itu disukai, diinginkan, dikejar, dihargai, berguna dan dapat membuat orang yang menghayatinya menjadi bermartabat. Peranan pendidikan sangat penting bagi manusia untuk meningkatkan kualitas hidup manusia itu sendiri

Pada konteks mikro pengembangan karakter berlangsungdalamkontekssuatusatuanpendidikan atau sekolah secara holistik (the whole school reform). Sekolah sebagai leading sector berupaya memanfaatkan dan memberdayakan semua lingkungan belajar yang ada untuk menginisiasi, memperbaiki, menguatkan, dan menyempurnakan secara terus-menerus proses pendidikan karakter di sekolah. Konteks mikro pengembangan nilai atau karakter merupakan latar utama yang harus difasilitasi bersama oleh Pemerintah Daerah dan Kementrian Pendidikan Nasional. Dengan demikian terjadi proses sinkronisasi antara pengembangan nilai atau karakter serta psikopedagogis di kelas dan di lingkungan sekolah, secara sosio-pedagogis di lingkungan sekolah dan masyarakat, dan pengembangan nilai atau karakter secara sosial-kultural nasional. Untuk itu sekolah perlu difasilitasi untuk dapat 
mengembangkan budaya sekolah (school culture). Pengembangan budaya sekolah ini perlu menjadi bagian integral dari pengembangan sekolah sebagai entitas otonom. Dengan demikian, setiap satuan pendidikan secara bertahap dan sistemik ditumbuhkembangkan menjad sekolah-sekolah yang dinamis dan maju (self-renewal schools).

Sehubungan dengan hal tersebut dalam Lontar Tutur Candrabhérawa yang merupakan karya sastra berbentuk teks banyak terdapat nilainilai pendidikan agama Hindu yang bermaksud untuk mengeluarkan arti yang terkandung dalam karya sastra tersebut, yaitu sebagai berikut.

\section{Sikap Beriman}

Sikap beriman atau yang dikenal dengan istilah sraddha dan bhakti dapat dilakukan dengan menjalankan puasa, rajin sembahyang, tapa brata dan sujud bhakti yang merupakan salah satu cerminan sikap beriman ke hadapan Tuhan Yang Maha Esa. Wujud bhakti kehadapan Ida Sang Hyang Widhi Wasa dengan menjaga segala ciptaan-Nya juga merupakan sikap beriman dan bertaqwa. Mendengarkan nyanyian suci, berdana punia yang tepat juga salah satu wujud bhakti kehadapan-Nya. Sikap beriman seseorang tidak terlihat dari luar diri seseorang tetapi dapat diketahui melalui perkataan dan perbuatannya dalam menjalani kehidupan.

Berdasarkan penggalan teks di atas dapat dicermati bahwa orang yang beriman senantiasa mempelajari isi dari kitab suci. Isi dari kitab suci diamalkan dalam kehidupan sehari-hari sehingga ketenteraman dunia dapat terwujud, seperti tokoh Yudhīștira sebagai wujud kebenaran abadi. Orang yang beriman akan senantiasa dapat melaksanakan segala pekerjaannya sehingga tantangan terberat pun dapat dijalankan. Orangorang beriman seperti tokoh Yudhīsțira akan dapat menemukan jalan kebebasan abadi baik di dunia dan di akhirat sebagai pahala dari menjalankan dharma agama. Oleh karena itu, sikap beriman dapat diwujudkan dengan menaati segala ajaran agama dan menjauhi larangannya agar terwujud moksartham jagaddhita ya ca iti dharma.

Religi merupakan perspektif sosiologis karena religi dipandang sebagai bagian dari makna sipnoptik. Hal ini menunjukkan kelemahan yang paling mendasar karena religi dalam pengertian agama merupakan prinsip dari segala prinsip dan asas dari segala asas (Shochib, 2010:1). Dalam dunia pendidikan, nilai religius perlu dikembangkan dalam diri remaja atau peserta didik.

Dalam penggalan teks tersebut juga dijelaskan keyakinan yang diajarkan oleh tradisi kuno, yang salah satunya adalah mendirikan parhyangan adalah sebuah bentuk religiusitas diri yang tercermin dalam wujud mendirikan tempat suci. Tempat suci sebagai tempat berstananya Ida sang Hyang Widhi sebagai simbol bhakti karena berkat Beliau dunia ini tercipta. Religiusitas akan semakin mendalam ketika umat manusia khususnya umat Hindu memahami hakikat pendirian parhyangan tersebut.

Dalam hubungannya dengan dunia pendidikan agama khususnya pendidikan agama Hindu, praktek dan terjun langsung ke lapangan dapat memudahkan siswa memahami pelaksanaan agama yang sesungguhnya. Pendirian parhyangan di rumah dapat menjadi contoh dan acuan anak didik untuk menumbuhkan jiwa keagamaan dan meyakini bahwa segala sesuatunya diciptakan oleh Ida Sang Hyang Widhi. Sehingga pendidikan sejenis ini dengan meningkatkan nilai religiusitas pada diri anak sangat relevan dengan konsep pendidikan karakter yang sedang berkembang di Indonesia saat ini.

\section{Cinta Tanah Air}

Pengertian dari cinta tanah air adalah suatu kasih sayang dan rasa cinta terhadap tanah kelahiran atau tanah airnya. Selain itu, cinta tanah air juga berarti perasaan sanubari warga negara untuk selalu mengabdi, memellihara, membela, dan melindungi tanah airnya dari segala ancaman. 
mencintai seni budaya dan tradisi yang terdapat di ruang masing-masing daerah dalam satu wilayah negara juga dapat dikatakan sebagai nilai cinta tanah air.

Nilai cinta tanah air bertujuan agar warga negara bangga akan bangsa dan negara sebagai tempat kelahirannya atau tanah airnya. Melupakan dan tidak mencintai tanah air sama halnya melupakan dan tidak mencintai ibu yang telah melahirkan kita.

Berikut ini adalah penggalan teks salinan Lontar Tutur Candrabhérawa yang menunjukkan nilai cinta tanah air, yaitu sebagai berikut (Tim Penyusun, 2004:8).

kaménanya rakwa pinaka tuhan ta, yéki anak inghulun, strī paripūrnéng hayu, sang anāma Dyah Ratna Śaśangka, ya pinaka tuhan ingwang, angdwa kasukșmaning dharma Śastra, sthiti bhakti kita ri sira, dadi swapitaning rātu wadhu, samangkana kita kabéh cihnan ta dharma satya ri kami,

Terjemahan:

Agar ada yang engkau jadikan jujunganmu, ini anakku, wanita yang kecantikannya amat sempurna, yang bernama Dyah Ratna Sangsaka. Dialah yang kujadikan taruhan, mengabdi kepada suksma (sari- sari) ajaran dharma. Berbaktilah engkau padanya, yang semuanya itu sebagai tuah raja perempuan. Demikianlah engkau semua, sebagai tanda setiamu padaku

Berdasarkan penggalan teks di atas menunjukkan bahwa Prabhu Candrabhérawa menjadikan anaknya, Dyah Ratna Sasangka, sebagai junjungan rakyatnya ketika Prabhu Candrabhérawa sudah kembali ke alam sunya. Seluruh rakyatnya hendaknya memperlakukan putrinya selayaknya memperlakukannya meskipun dirinya telah tergantikan oleh Dyah Ratna Sasangka. Oleh karena itu, seluruh rakyat Kerajaan Dewantara yang telah menjadi pengikut dari Raja Candrabhérawa menunjukkan nilai cinta tanah airnya dengan berbakti kepada penerus dari Raja Candrabhérawa meskipun beliau sudah kembali ke alam sunya.

\section{Sikap Peduli Lingkungan}

Perkembangan nilai atau karakter pada individu dipengaruhi oleh faktor bawaan (nature) dan faktor lingkungan (nurture) (Zubaedi, 2011:109). Karakter peduli lingkungan merupakan sikap dan tindakan yang selalu berupaya mencegah kerusakan pada linkungan alam sekitar dan mengembangkan upaya-upaya untuk memperbaiki kerusakan alam yang terjadi. Lingkungan yang baik dapat menciptakan suasana yang mendorong tumbuh kembangnya nilai- nilai pendidikan karakter. Upaya pendidikan karakter merupakan upaya yang harus melibatkan semua pihak. Pembentukan dan pendidikan karakter akan terjadi jika dari proses pendidikan terdapat kesinambungan dan keharmonisan pada lingkungan pendidikan.

Menurut Megawangi (dalam Noor, 2012:87) bahwa anak-anak akan tumbuh menjadi pribadi yang berkarakter apabila dapat tumbuh pada lingkungan yang berkarakter sehingga fitrah setiap anak yang dilahirkan suci dapat berkembang secara optimal. Mengingat lingkungan anak bukan saja lingkungan keluarga yang bersifat mikro, maka semua pihak keluarga, sekolah, media massa, komunitas bisnis, dan sebagainya turut andil dalam perkembangan karakter anak. Begitu pentingnya lingkungann bagi tumbuh kembang manusia dalam membentuk dan membangun nilainilai pendidikan karakter dalam dirinya. Maka manusia perlu merawat dan menjaga lingkungan agar tercipta suasana lingkungan yang harmonis dan dapat mendukung proses tumbuh kembangnya penddikan karakter. Terkait dengan hal tersebut, dalam Lontar Tutur Candrabhérawa mengenai pentingnya lingkungan dan sikap peduli terhadap lingkungan diperlihatkan dalam ucapan Prabhu Sri Candrabhérawa berikut ini (Tim Penyusun, 2004:13).

yan harěp maněmbah kayu-kayu, apan ikang Sanggar Arca sarwa taru, rahayu hanéng tuwuhanya sěmbahěn

Terjemahan:

Jika berharap memuliakan kayu-kayu, bukanlah sanggar dan arca, semuanya 
itu berasal dari kayu. (Maka lebih baik) kelestariannya tumbuh subur ditempatnya yang dipuja. Tidak usah berbuat percuma dalam pikiran

Berdasarkan penggalan teks tersebut di atas terdapat suatu keyakinan bahwa salah satu cara untuk mewujudkan bhakti kepada Tuhan adalah dengan cara menjaga kesejahteraan makhluk hidup dan alam lingkungan. Karena dengan sikap peduli lingkungan. manusia dapat hidup harmonis dan sejahtera. Oleh karena itu, lingkungan harus dilihat sebagai sesuatu yang memiliki nilai teologis, sebab alam ini dianugrahkan oleh Tuhan untuk dikelola sebaik mungkin untuk kemakmuran semua orang dan alam ini juga dapat dijadikan sebagai sarana pemujaan terhadap Tuhan Yang Maha Kuasa (Donder, 2011:96). Dengan kata lain, lingkungan yang berkualitas dan adanya tanggung jawab semua pihak, maka perkembangan nilainilai pendidikan karakter pada anak didik dapat lebih optimal.

\section{Sikap Hormat}

Manusia tidak dapat hidup sendiri maka disebut dengan makhluk sosial yang selalu berinteraksi dengan orang lan. Menjalaniberbagai kehidupan dengan orang lain, dibutuhkan sikap saling menghormati antara sesama agar terjalin hubungan yang harmonis. Sikap hormat ditunjukkan dengan sapaan yang ramah, tunduk kepada atasan, bersikap rendah hati kepada yang lebih tua dan menghargai orang lain. Hal ini sesuai dengan penggalan teks salinan Lontar Tutur Candrabhérawa yaitu sebagai berikut (Tim Penyusun, 2004:8).

\section{Ling Śrī Candrabhérawa:" Dhū kakingku kita Bhimaséna, bhagé kamayangan kita dhatěng marangké, ngké-ngké kita alungguh ira samipa ning nghulun, hanéng singhāsana palungguhanta".}

Terjemahan:

Kata Sri Candrabhērawa: "Wahai, cucuku Sang Bhimasena! Bahagialah engkau datang kesini. Duduklah disampingku, pada kursi tempat dudukmu".

Berdasarkanpenggalantekstersebutdijelaskan secara implisit bahwa Prabhu Candrabhérawa memperlakukan tamu secara hormat dan penuh ramah tamah. Beliau memperlakuan Bhima seolah-olah cucunya yang telah datang dari jauh untuk tiba di Kerajaan Dewantara. Prabhu Candrabhérawa tidak memperhitungkan tujuan dari Bhima sebelum mempersilahkan tamunya untuk duduk dan menikmati seluruh hidangan yang disajikan.

\section{Tepat Janji (Satya)}

Sikap tidak ingkar akan kata-kata, selalu mengedepankan kebenaran merupakan cerminan dari sikap tepat janji. Menjalani kehidupan dengan nilai kejujuran memang tidaklah mudah, perlu pemahaman dan penanaman nilai luhur budi pekerti agar dapat terlaksana. Maka kepercayaan orang lain dapat dipertanggunjawabkan dengan nilai kebenaran (tepat janji). Hal ini sejalan dengan pendapat Titib (2006:276) djelaskan bahwa nilai tepat janji yaitu sikap dan perilaku yang menunjukkan keterikatan yang bertanggung jawab terhadap apa yang telah disetujui, baik pada diri sendiri ataupun bersama orang lain, hal ini diwujudkan dalam perilaku yang selalu konsisten dengan apa yang telah dinyatakan, baik melalui kata-kata, perencanaan, niat maupun itikad. Seperti dalam penggalan teks salinan Lontar Tutur Candrabhérawa di bawah ini (Tim Penyusun, 2004:32).

Ling Śri Déwāntara; "Sajña Aji Mahārāja Dharmaputra, pahalawan ta angěn-angĕn Praméśwara, apan hana punagi mami ri kita prabhū, i Sang kumawruhi swacitta mami, hana putri mami, Ni Ratna Śangśaka ngaran iki, wirüpa mudha duryaśa, astamyan tuhwāsih Paraméśwara, wĕnang pinaka padyārgha Sang Bhūpati, ngimpunakēn jöng Bhüpati, tumūt warahan ta ring paramārtha ning pariwara, hétunyan wruha ri gati-gati ning, karma sanyaşa, nganūtakĕn sadédé singgih paraméśwara”. Mangkana Ling Śrī Déwāntara. 
Terjemahan:

Kata Raja Candrabhèrawa: "Ampun maharaja Yudhīsțira, berbahagialah pikiran paduka Maharaja, sebab ada kaul hamba kepada paduka Maharaja, bahwa siapa yang tahu isi pikiranku, maka ini putriku, Dyah Ratna Śaśangka namanya ini, wajahnya kurang memuaskan, jika berkenan paduka Maharaja, patutlah sebagai pelayan tuanku Maharaja, berkumpul pada duli tuanku Maharaja, mohon diajari tentang tatacara sebagai abdi, sehingga dia tahu tentang perilaku karma sanyasa, menuruti petunjuk Paduka Maharaja”. Demikian kata Raja Candrabhèrawa.

Berdasarkan penggalan teks tersebut di atas tercermin bahwa Raja Candrabhérawa memenuhi janjinya setelah ia kalah mengadu kesaktian dengan Raja Yudhīștira. Prabhu Candrabhérawa menyerahkan putrinya kepada Raja Yudhīștira karena telah mengalahkannya. Raja Candrabhérawa telah memenuhi janjinya sebagai wujud kșatriya yang harus setia kepada kata-kata.

\section{Penutup}

Struktur intrinsik Lontar Tutur Candrabhérawa membawa kita mengenal lebih dekat terhadap karya sastra tersebut. Dalam analisis yang telah dilakukan dapat diketahui bahwa struktur intrinsik Lontar Tutur Candrabhérawa dibagi menjadi beberapa pokok sub bahasan, yaitu insiden, alur (plot), tokoh dan penokohan, tema, latar, dan amanat. Tokoh utama dari karya sastra tersebut adalah Prabhu Yudhīṣtira, Sri Kṛṣna, dan Raja Candrabhérawa dengan beberapa tokoh tambahan yaitu Brahma, Wisnu, Bima, Arjuna, Nakula, Sahadewa, dan Patih Kiratha. Amanat yang disampaikan adalah bahwa dalam menjalankan sebuah agama, khususnya agama Hindu harus dilandasi dengan rasa bhakti dan segala sesuatu yang dilakukan harus didalami maknnya (tattwa).
Fungsi pendidikan agama Hindu pada rumusan masalah kedua dapat diketahui bahwa Lontar Tutur Candrabhérawa memiliki fungsi dalam bidang pendidikan agama Hindu, yaitu tattwa, etika dan acara. Ketiga fungsi pendidikan agama Hindu tersebut apabila dihubungkan dengan pendidikan modern berkaitan dengan pengembangan fungsi kognitif, afektif, dan psikomotor. Dalam aspeknya sebagai fungsi kognitif, karya sastra Lontar Tutur Candrabhérawa memberikan pengetahuan dari segi tattwa terutama dalam kaitannya dengan ajaran-ajaran agama Hindu. Demikian pula halnya dengan pengembangan aspek fungsi afektif yang turut memberikan sumbangan terhadap pembentukan susila atau etika yang berupa ajaran-ajaran selama hidup di dunia yang dapat dipetik dari karya sastra tersebut. Sedangkan fungsi psikomotor dalam bidang pendidikan yang dapat diambil dariLontar Tutur Candrabhérawa adalah segala sesuatu di dunia ini juga turut disucikan dan dibersihkan melalui acara atau kebiasaan-kebiasaan yang dalam hal ini adalah dalam bentuk upacara. Oleh karena itu, dapat ditarik simpulan dalam analisis fungsi pendidikan adalah bahwa Lontar Tutur Candrabhérawa memberikan kontribusi fungsi tattwa, susila dan acara yang tertuang dalam prosa yang sarat dengan pendidikan agama Hindu.

Nilai-nilai pendidikan agama Hindu yang terdapat dalam Lontar Tutur Candrabhérawa adalah sikap beriman, cinta tanah air, peduli lingkungan, sikap hormat, dan tepat janji. Kelima nilai-nilai pendidikan tersebut terdapat dalam Lontar Tutur Candrabhérawa sehingga karya sastra ini sangat relevan dengan konsep pendidikan karakter yang ada di Indonesia. Analisis nilai-nilai pendidikan ini memberikan gambaran bahwa sebuah karya sastra terlebih lagi karya sastra jaman dahulu memberikan kontribusi terhadap penanaman dan penumbuh-kembangan nilai-nilai universal, khususnya karakter yang menjadi harus dikembangkan di rumah, sekolah, dan di masyarakat. 


\section{Daftar Pustaka}

Ahmadi, H. Abu dan Nur Uhbiyati. 2001. Ilmu Pendidikan. Jakarta: PT Rineka Cipta

Arikunto, Suharsini. 2009. Dasar-Dasar Evaluasi Pendidikan. Jakarta: Bumi Aksara

Artini, Ni Komang Suci. 2014. "Babad Tutuan (Perspektif Pendidikan Agama Hindu)". Denpasar: PPs IHDN Denpasar

Balya, M.Danial. 2012. "Hermeneutika Teologis Bultmänn Usaha Memberi Arah pada Soal Glauhen dan Verstehen". Dalam Edi Mulyono, dkk. Belajar Hermeneutika. Yogyakarta: IRCiSod Halaman:118-140

Damai, I Ketut. 2014. "Nilai-Nilai Pendidikan Keluarga Hindu dalamTeks Sarasamuccaya" (Tesis). Denpasar: PPs IHDN Denpasar

Esten, Mursal. 1982. Sastra Indonesia dan Tradisi Subkultur. Surabaya: Usaha Nasional

Kaelan. 2005. Metode Penelitian Kualitatif Bidang Filsafat. Yogyakarta: Paradigma

Keraf, A. Sony. 2001. Ilmu Pengetahuan Sebuah Tinjauan Filosofis. Yogyakarta: Kanisius

Kusuma, I Nyoman Weda. 2005. Kakawin Usana Bali Karya Danghyang Nirartha: Suntingan Teks, Terjemahan, dan Telaah KonsepKonsep Keagamaan. Kuta: Pustaka Larasan

Lubis, Mochtar. 1984. Bangsa Indonesia: Bangsa Indonesia (Masa Lampau-Masa Kini-Masa Depan). Jakarta: Inti Idayu Press

Mulyana, Dedi. 2001. Metodelogi Penelitian Kualitatif, Paradigma Baru Ilmu Komunikasi dan Ilmu Susila Lainnya. Bandung: Remaja Rosdakarya

Noor, Rohinah M. 2012. Mengembangkan Karakter Anak secara Efektif di Sekolah dan di Rumah. Yogyakarta: PT Insan Madani

Nurgiantoro, Burhan. 1995. Teori Pengkajian Fiksi. Yogyakarta: Gadjah Mada University Press Poedjawijatna, I.R. 1982. Etika Filsafat Tingkah Laku. Jakarta: Bina Aksara

Ratna, Nyoman Kutha. 2012. Teori, Metode, dan Teknik Penelitian Sastra. Yogyakarta: Pustaka Pelajar

Satori, Djam'an dan Komariah, Aan. 2009. Metodologi Penelitian Kualitatif. Bandung: Alfabeta

Semi, M. Atar. 2012. Metodologi Penelitian
Sastra. Bandung: CV Angkasa

Shochib, Moh. 2010. Pola Asuh Orang Tua dalam

Membantu Mengembangkan Disiplin Diri

Sebagai Pribadi yang Berkarakter. Jakarta: Rineka Cipta

Suastika, I Made. 2006. Estetika Kreativitas Penulisan Sastra dan Nilai Budaya Bali. Denpasar: Fakultas Sastra UNUD

Sudikan, Setiyoyuana. 1998. Penelitian Penyususnan Karya Ilmiah. Semarang: Aneka Ilmu

Sudjiman, Panuti. 1988. Memahami Cerita Rekaan. Jakarta: Pustaka Jaya

Sugiyono. 2010. Metode Penelitian Pendidikan (Pendekatan Kuantitatif, Kualitatif, dan $R \& D)$. Bandung: Alfabeta

Sukada, I Made. 1987. Unsur Insiden dan Perwatakan dalam Fiksi. Denpasar: Widya Pustaka University Udayana Press

Supena, Ilyas. 2012. "Hermeneutika Teologis Rudolf Bultmänn". Dalam Edi Mulyono, dkk. Belajar Hermeneutika. Yogyakarta: IRCiSod. Halaman: 96-117

Sura, I Gede. 1985. Pengendalian Diri dan Etika dalam Ajaran Agama Hindu. Jakarta: Hanuman Sakti , dkk. 2002. Kajian Naskah Lontar Siwagama. Denpasar: Dinas Kebudayaan Propinsi Bali

Suweta, I Made. 2012. "Nilai Sosial Budaya Hindu Dalam Kakawin Ramaparasuwijaya”. Dalam Sphatika Jurnal Teologi Volume 7 No. 2, Desember 2012. Denpasar: Fakultas Brahma Widya IHDN Denpasar. Halaman: 22-33

Teeuw, A. 1983. Membaca dan Menilai Sastra. Jakarta : Gramedia.

1984. Sastra dan Ilmu Sastra: Pengantar Teori Sastra. Jakarta: Pustaka Jaya

1991. Khasanah Sastra Indonesia. Jakarta: Balai Pustaka

Tim Penyusun. 2004. Tutur Candrabhérawa. Denpasar: Dinas Kebudayaan Provinsi Bali Tim Penyusun. 2005. Kamus Istilah Agama Hindu. Denpasar: Kantor Departemen Agama Propinsi Bali

Tim Penyusun. 2008. Kamus Besar Bahasa Indonesia Pusat Bahasa Edisi Keempat. 
Jakarta: PT Gramedia

Titib, I Made. 2006. "Persepsi Umat Hindu di Bali terhadap Svarga, Naraka, dan Moksa dalam Svargarohanaparva: Perspektif Kajian Budaya (Disertasi)". Surabaya: Paramita

Wiana, I Ketut. 1997. Cara Belajar Agama Hindu yang Baik. Denpasar: Yayasan Dharma Narada

Widari, Anak Agung Istri. 2015. "Teologi Hindu dalam Teks Tutur Candrabhérawa" (Tesis). Denpasar: Pps IHDN Denpasar

Zubaedi. 2011. Desain Pendidikan Karakter: Konsep dan Aplikasinya dalam Lembaga Pendidikan. Jakarta: Kencana 